\title{
Experimental Analysis of Sandstone and Travertine
}

\author{
T. Doležel, M. Drdácký, P. Konvalinka, L. Kopecký
}

Sandstone and travertine are sedimentary rocks. The former is clastic, while the latter is sourced by chemical precipitation from hot springs. Their applications in civil engineering structures are mostly influenced by the ability to carry compression loading. A three-point bending experiment is usually used to determine material characteristics. However it does not correspond very well to applicatiosn in structures. For this reason we used a uniaxial compression test to obtain the modulus of elasticity and the stress-strain diagram. To obtain detailed information about the crystalline structure of sandstone and travertine a microscopic analysis wascarried out, using optical microscopy and an EDAX multichannel spectrometer for elementary microanalysis.

Keywords: sandstone, travertine, EDAX point analysis, microscopic analysis, stress-strain diagram in compression, modulus of elasticity.

\section{Introduction}

The sandstone and travertine that we tested are brittle materials. A three-point bending experiment is usually used to investigate their material parameters. However, because of the brittleness of the materials and their application in engineering structures, it was found that a uniaxial compression test is more appropriate. If the loading is performed by increasing the deformation in the course of the experiment, we can obtain a stress-strain diagram including a part of the descending branch of the curve, and we can observe the compressive softening. If we use the same methodology for an experimental investigation of a different type of engineering materials we have an opportunity to compare their material characteristics. Together with detailed information about the mineralogical composition and rock structure from a by microscopic analysis we can obtain efficient calculation data.

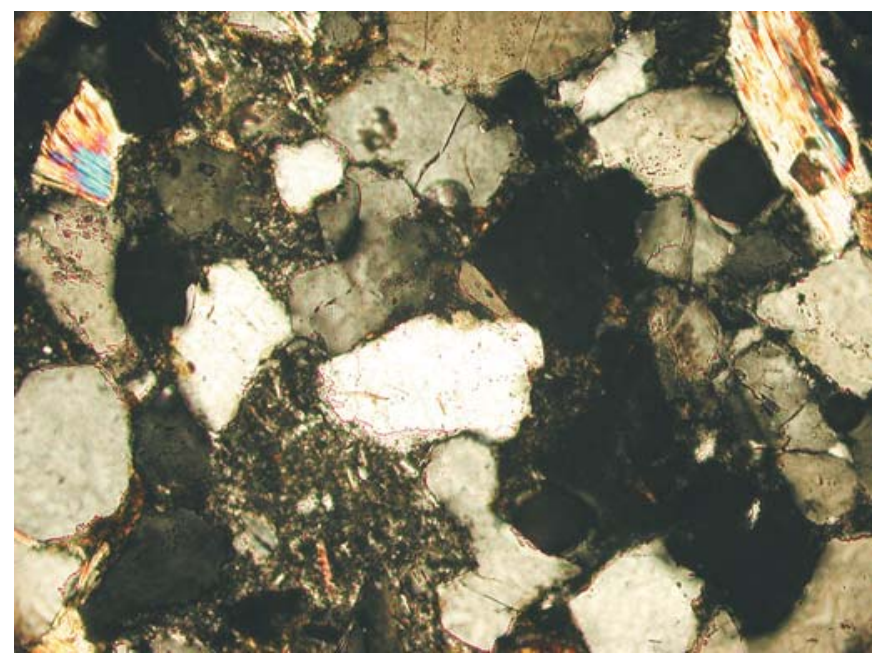

Fig. 1: Micrograph of a thin section of sandstone (in crossed nicols, $M=200$ )

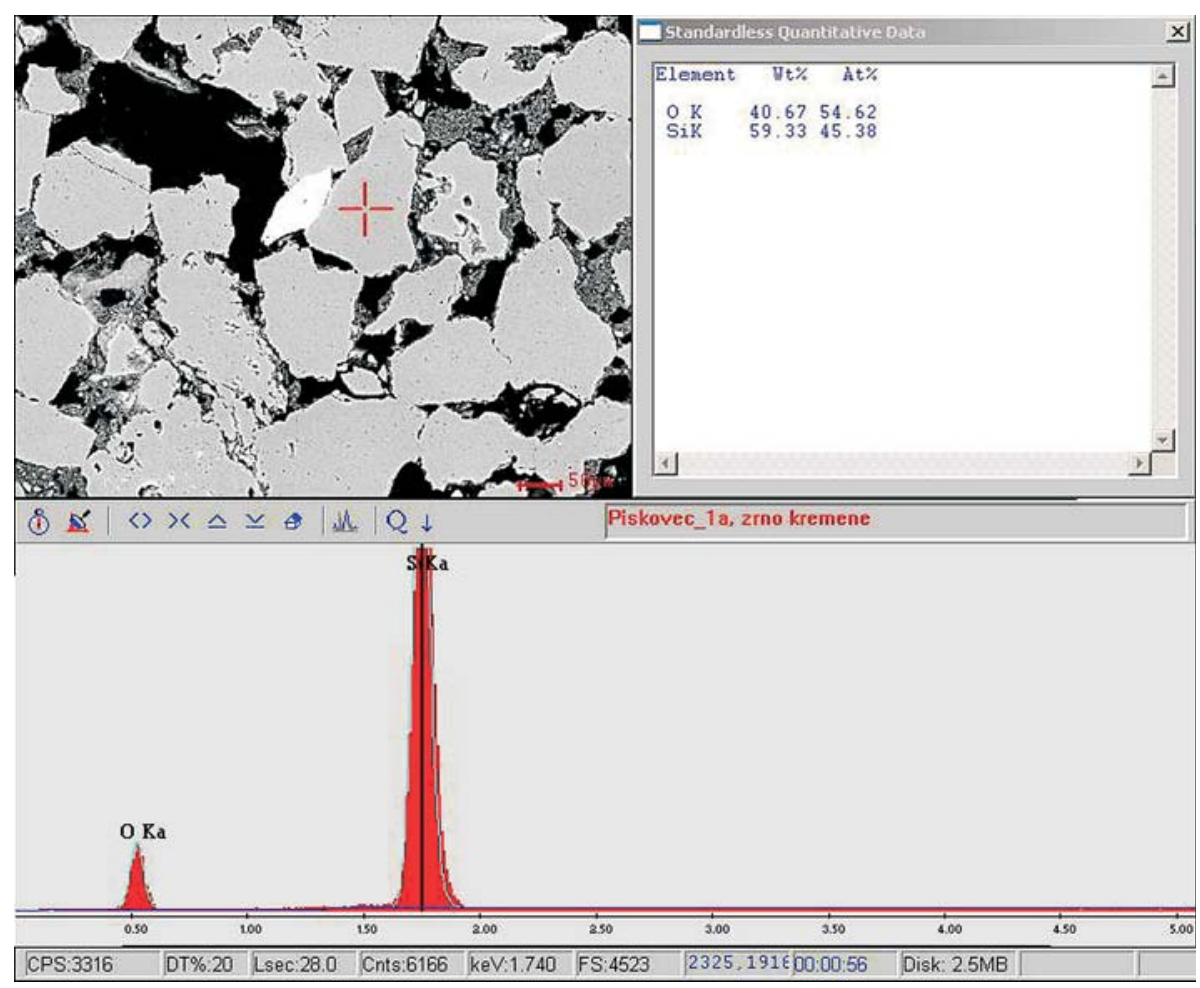

Fig. 2: EDAX point analysis of quartz braun. Very pure quartz without accessories 


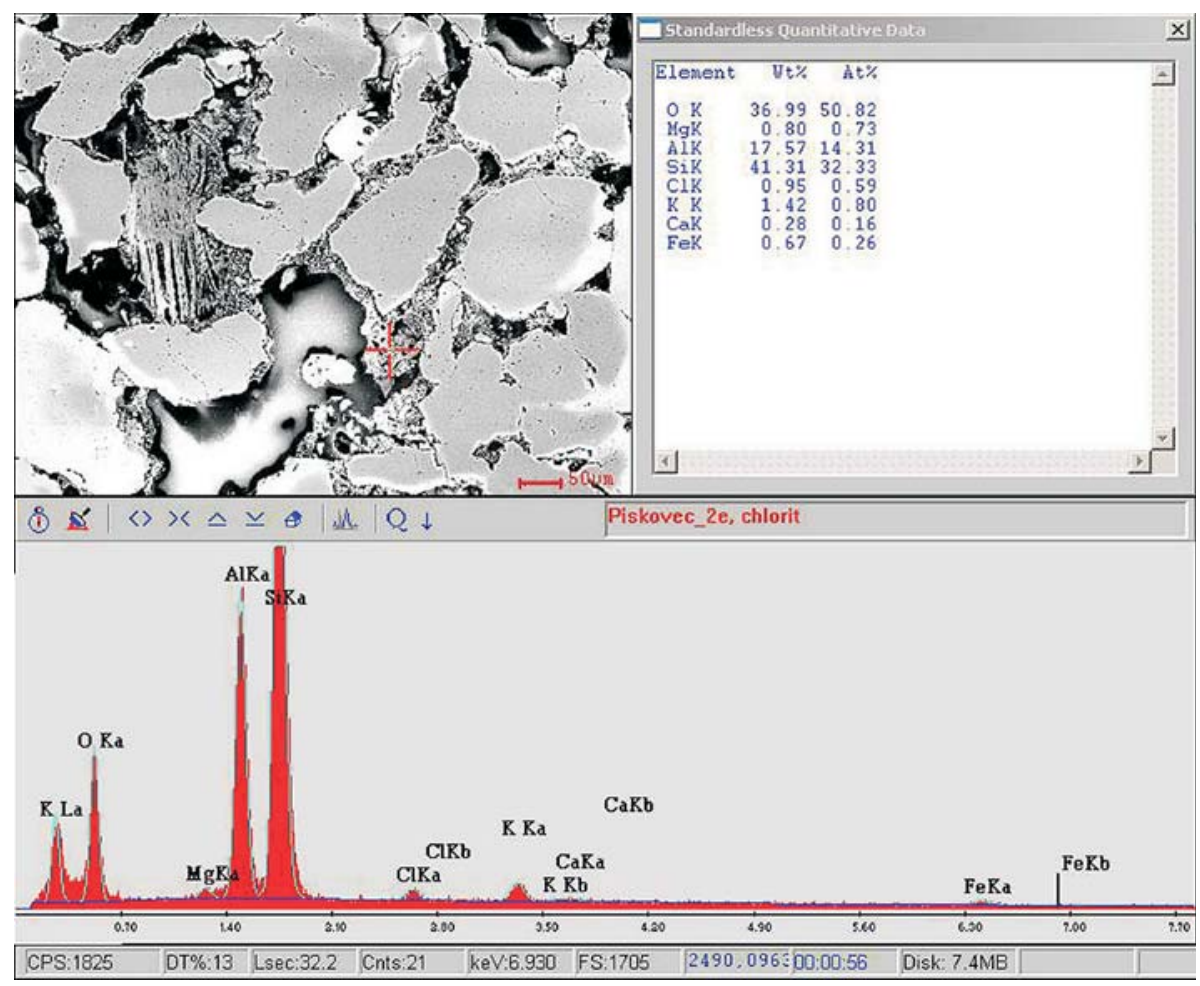

Fig. 3: EDAX point analysis of the chlorite group minerals in the cement matrix of the rocks. Probably diabanite

\section{Experimental}

All the experimental tests were prepared in the laboratory of the Department of Structural Mechanics at the Faculty of Civil Engineering of CTU in Prague.

The uniaxial compression tests were carried out using the GROND DSM 2500 apparatus, which consists of a stiff loading frame, and is provided with a hydraulic servomechanism which was used when loading a specimen under deformation control. A constant strain rate of $10^{-5}$ was used. The axial strains were measured by means of tensometric strain gauges located on the loading frame. SANDNER EXA strain gauges were used, with the measuring base equal to $10 \mathrm{~mm}$. Special care was taken when preparing the specimens [1]. In accordance with the pilot tests the sizes of the prism specimens were specified as $50 \times 50 \times 200 \mathrm{~mm}$. Five specimens of each material were investigated. Those tests providing the maximum and minimum values were ignored.

The microstructure of the specimen was observed on the XL 30 ESEM-TMP PHILLIPS environmental scanning electron microscope equipped with an EDAX multichannel spectrometer for elementary microanalysis. The ESEM mode facilitates measurement at a different vacuum level and in a chamber with different environmental conditions.

\subsection{Sandstone}

In the case of sandstone we recognized that the sedimentary rock consists of clastic grains and cement. Almost $99 \%$ of the grains are quartz particles. The cement consists of chlorites, clay minerals and limonite. The microscopic pattern in the crossed nicols of a thin section of the sandstone is shown in Fig. 1. A grey palette of quartz grains, dark coloured particles of biotite and microcrystallic aggregate of chlorite minerals and white limonite, can be seen.

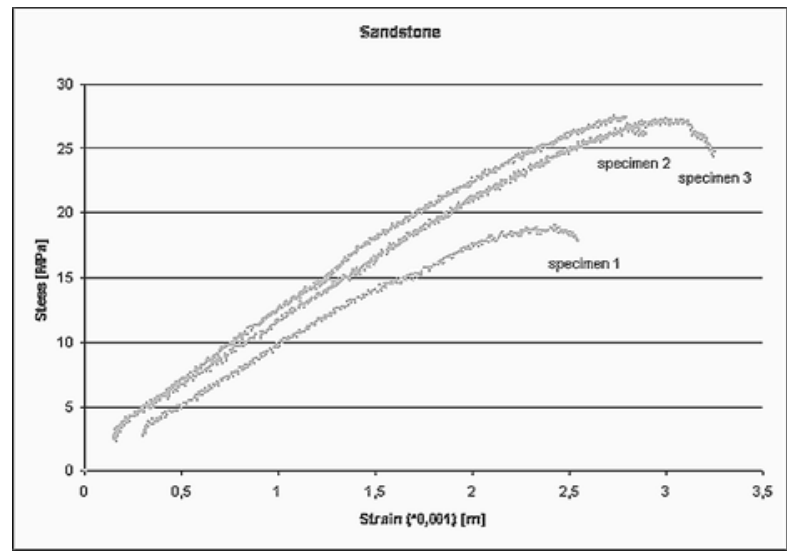

Fig. 4: Stress-strain diagram of a sandstone specimen

The highest strength of the sandstone specimen was achieved by specimen No. 2 (see Fig. 4). Its maximum strength was 27.5 MPa. The average value of the modulus of elasticity was found to be $11.85 \mathrm{GPa}$.

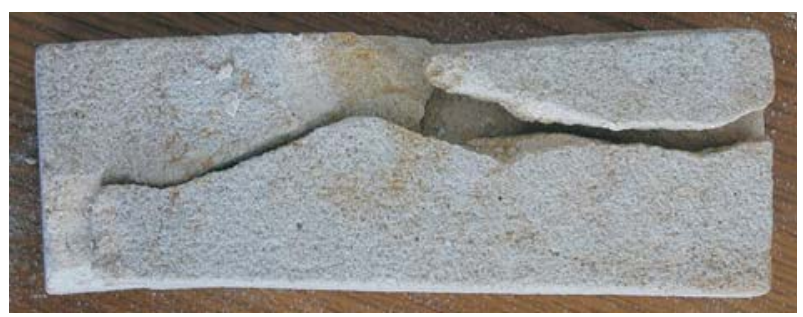

Fig. 5: Specimen of sandstone after the experiment 


\subsection{Travertine}

From the point of view of the mineralogical composition, travertine is a simpler but a structurally very porous rock, consisting of aragonite and of clay minerals and chlorites. The microscopic pattern of a thin section of travertine is shown in Fig. 6. Allotriomorphous particles of aragonite and gray agglomerates of clay minerals and chlorites filled with finely dispersed limonite can be observed.

The highest strength of a travertine specimen was found for specimen No. 3 (see Fig. 9). The maximum strength reached 50.8 $\mathrm{MPa}$. The average value of the modulus of elasticity was $20.19 \mathrm{GPa}$.

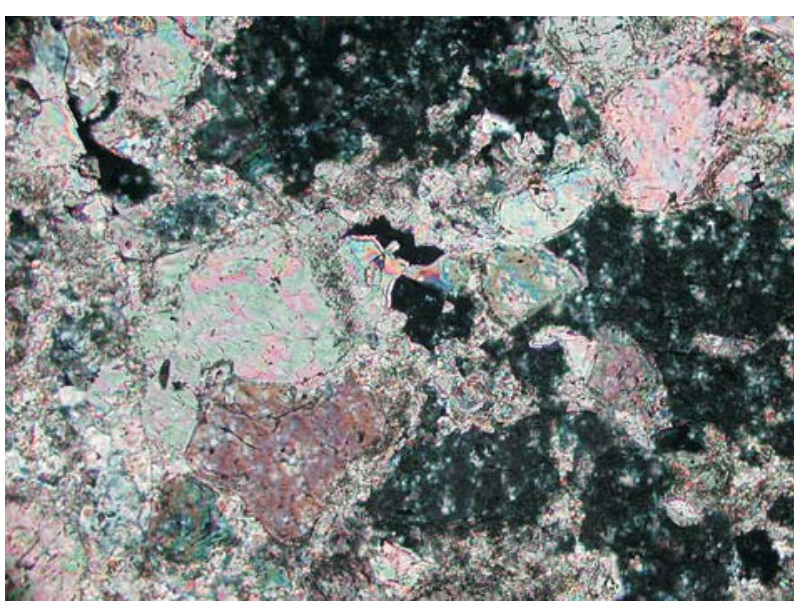

Fig. 6: Micrograph of travertine (in crossed nicols, $M=100$ )

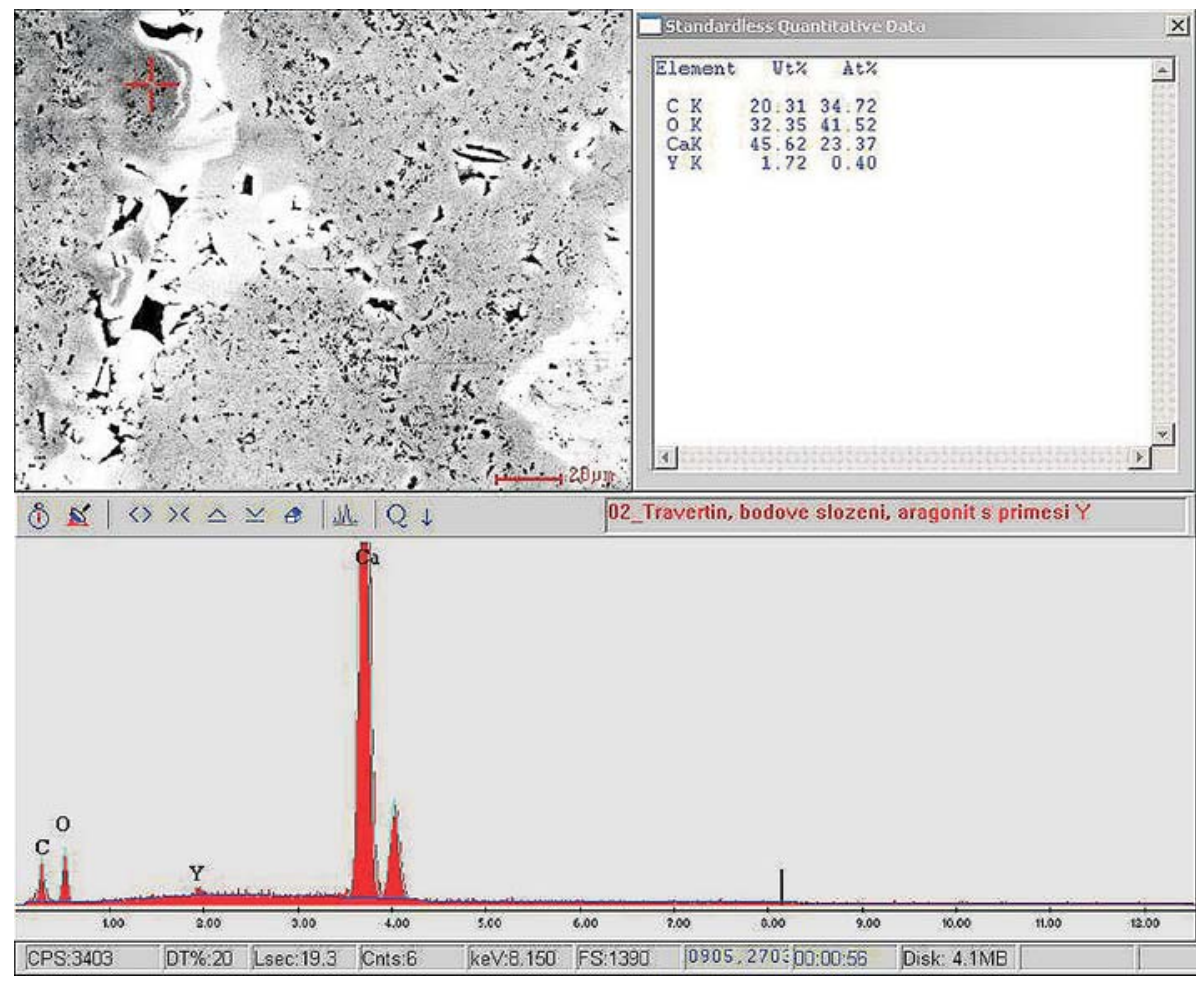

Fig. 7: EDAX point analysis of travertine (aragonite)

\section{Conclusion}

This work has presented an experimental analysis of the material characteristics of sedimentary rocks: sandstone and travertine. The strength and modulus of elasticity in uniaxial compression and the microstructural analysis of the specimen were investigated. The results show that:

- the use ofuniaxial compression tests for determining the material characteristics provides more efficient data for calculations,

- knowledge of the microstructure of sedimentary rocks enables a comparison of the different materials and their material characteristics,

- it is useful to have a database of such materials which contains all the required engineering parameters.

\section{Acknowledgment}

This work on an experimental investigation of sandstone and travertine was supported by the Ministry of Education of the Czech Republic under grant No. MSM 210000004.

\section{References}

[1] Konvalinka P. et al.: "Methodics of determination of mechanical characteristics of concrete in compression." Workshop CTU, Prague, 2000, pp. 250-251.

[2] Snethlage R., Meinhardt-Degen J.: "Requirements for re-treating natural stone facades. An overview over the assessment parameters." Bavarian State Department of Historic Monuments, Munich, Germany, 2002. 


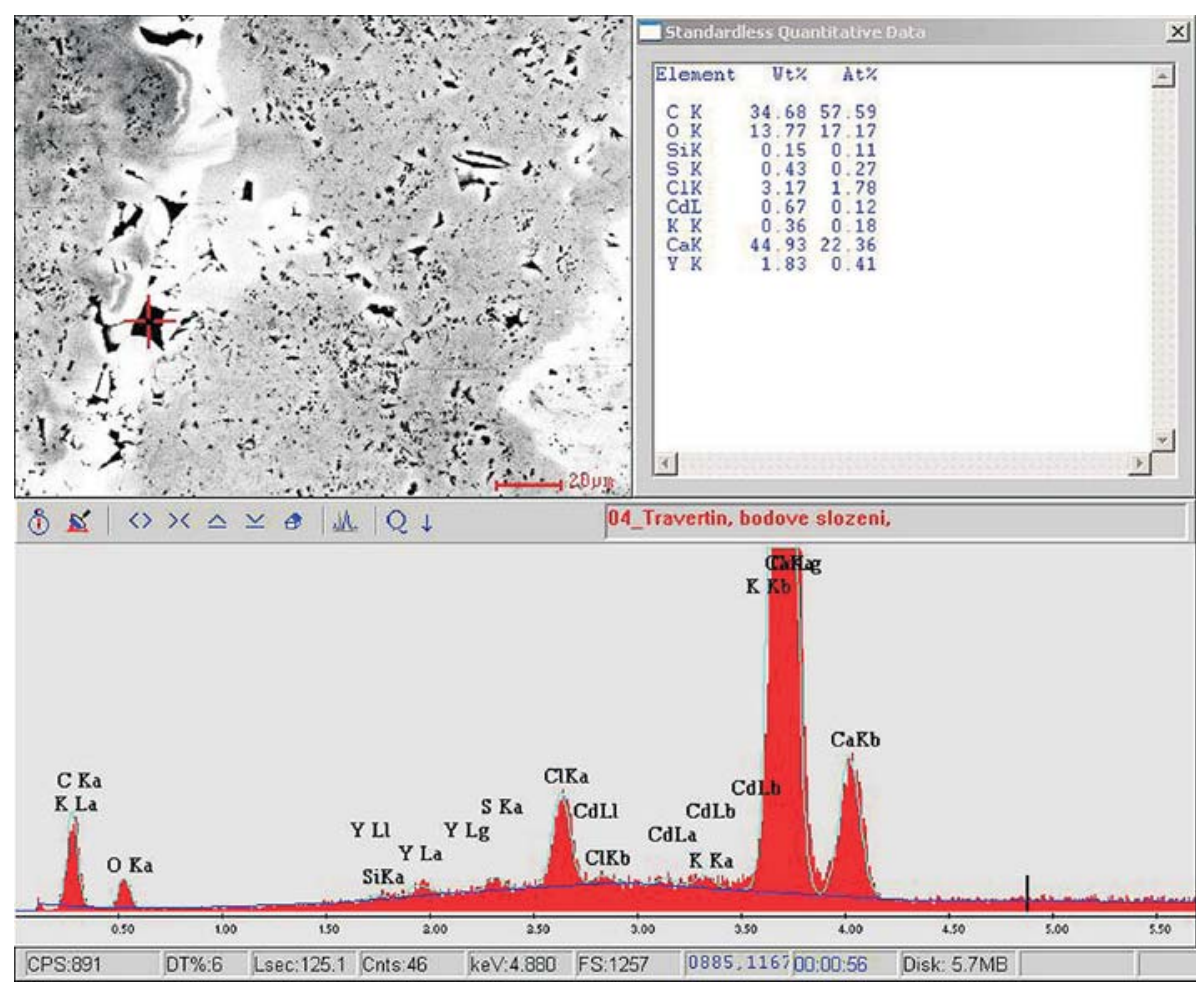

Fig. 8: EDAX point analysis of the interstitial matrix of travertine - clay minerals and chlorites

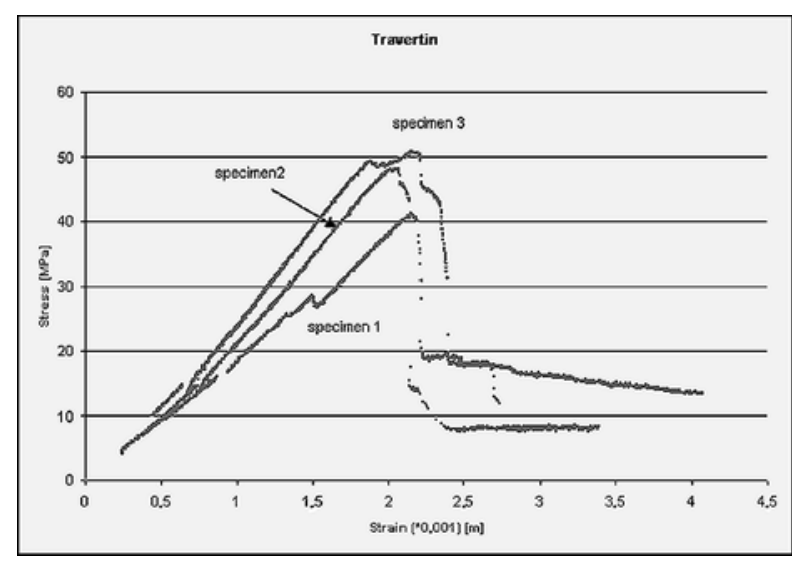

Fig. 9: Stress-strain diagram of a travertine specimen

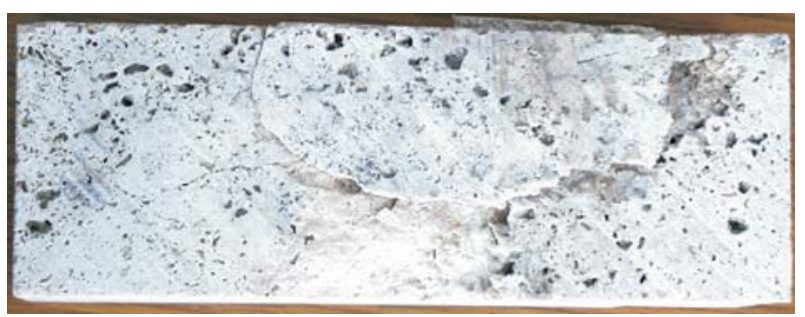

Fig. 10: Specimen of travertine after the experiment
Ing. Tomáš Doležel

phone: +420224355417

e-mail: tomas.dolezel@fsv.cvut.cz

Dept of Structural Mechanics

Czech Technical University in Prague Faculty of Civil Engineering

Thákurova 7

16629 Praha 6

Ing. Miloš Drdácký, DrSc.

phone: +420 286885382

fax: +420 286884634

e-mail:drdacky@itam.cas.cz

\section{ÚTAM AV ČR}

Prosecká 76

19000 Praha 9, Czech Republic

Doc. Ing. Petr Konvalinka, CSc.

phone: +420224354306

e-mail: conwa@fsv.cvut.cz

RNDr. Lubomír Kopecký

phone: +420224354823

e-mail: lubomir.kopecky@fsv.cvut.cz

Dept of Structural Mechanics

Czech Technical University inPrague

Faculty of Civil Engineering

Thákurova 7

16629 Praha 6, Czech Republic 